\title{
How Can We Treat Asymptomatic Carotid Disease in Patients with a Planned CABG?
}

\section{(D) Veysel Kutay}

University of Health Sciences, İstanbul Mehmet Akif Ersoy Hospital, Clinic of Cardiovascular Surgery, İstanbul, Turkey

\begin{abstract}
Carotid artery intervention to the neurological asymptomatic patients is one of the most controversial issues of vascular surgery throughout the last decades. The decision about how to manage asymptomatic carotid disease in the setting of planned coronary artery bypass graft (CABG) becomes more complex due to surgical treatment of either pathology may be complicated by multiple factors. Current guidelines do not support routine screening for carotid artery stenosis before $\mathrm{CABG}$ because of given the low prevalence of stroke after CABG. Optimal surgical intervention and timing for patients having concomitant severe carotid and coronary artery stenosis remains uncertain. In this brief review, we analyze the incidence of significant carotid stenosis in patients undergoing $\mathrm{CABG}$, association of untreated
\end{abstract}

asymptomatic carotid stenosis on postoperative stroke, effects of carotid endarterectomy (CEA) on postoperative incidence of stroke, determination of surgical options and technical variations for CEA, scanning methods for identifying the vulnerable carotid plaque and revealing risk factors and predictors associated with stroke after CABG. Synchronous or staged CEA still remain valuable options in order to diminish postoperative risk of stroke for neurologically asymptomatic patients undergoing to $\mathrm{CABG}$ who have bilateral significant carotid artery stenosis or contralateral occlusion.

Keywords: Carotid endarterectomy, carotid stenosis, coronary artery bypass, stroke

Address for Correspondence: Veysel Kutay, University of Health Sciences, İstanbul Mehmet Akif Ersoy Hospital, Clinic of Cardiovascular Surgery, İstanbul, Turkey

Phone: +90 5337771173 e-mail: vkutay@yahoo.com ORCID: orcid.org/0000-0002-5822-5259

Received: 17.02.2019 Accepted: 05.09.2019

Cite this article as: Kutay V. How Can We Treat Asymptomatic Carotid Disease in Patients with a Planned CABG?

EJCM 2019;7(3):109-116.

DOI: 10.32596/ejcm.galenos.2019.02.07

${ }^{\circ}$ Copyright 2019 by Heart and Health Foundation of Turkey (TÜSAV) / E Journal of Cardiovascular Medicine published by Galenos Publishing House. 


\section{Introduction}

Stroke is the most dreadful complication of all cardiac surgery procedures and remains an important cause of mortality and permanent disability. In Europe, stroke is responsible for 1.1 million deaths each year, making it second commonest cause of death and more than half of all stroke survivors remain dependent on others for daily activities ${ }^{(1)}$. Following the introduction of carotid endarterectomy (CEA) in 1954 for the prevention of stroke in symptomatic patients, an increasing proportion of carotid interventions were undertaken in neurologically symptomatic patients ${ }^{(2)}$. Uncertainty about the ideal treatment of these patients makes it essential for us to understand about the causes of stroke. Usually, all our attention were directed on carotid disease as being a key source of stroke but forgetting that there are many other important causes as well. The mechanisms underlying development of post-operative stroke are multiple and mostly of cardiac origin as thromboembolism may occur from left sided heart chambers and ascending aorta ${ }^{(3)}$. Patients with severe carotid artery stenosis undergoing coronary artery bypass graft $(\mathrm{CABG})$ face a higher risk of stroke than patients without carotid disease but most strokes are unrelated to carotid disease ${ }^{(4,5)}$. Although several strategies have been developed for minimize to peri-operative stroke such as avoiding the manipulation of ascending aorta, prompt treatment of arrhythmias and low cardiac output, minimizing aortic cannulation or using offpump bypass techniques, optimal regulation of metabolic state and cerebral perfusion, the prevalence of stroke in cardiac surgery patients with no evidence of significant carotid artery stenosis was found $1.8 \%{ }^{(6,7)}$.

The indication to treatment of patients with carotid disease should consider neurological symptomatology, degree of carotid stenosis, medical comorbidities, vascular and local anatomical features and carotid plaque morphology.

Neurological status is obviously an important predictor for stroke after CABG. It means that symptomatic patients are more vulnerable to compromised cerebral circulation during cardiopulmonary bypass. Patients were considered to be asymptomatic if they had no ipsilateral neurologic events of stroke, transient ischemic attack (TIA) or amaurosis fugax within the 6 months prior to the procedure. This definition used by ACST collaborative group which stated that neurologic symptoms older than 6 months should be considered asymptomatic because the risk of recurrent stroke decreases over time ${ }^{(8)}$.

Carotid artery intervention to the neurological asymptomatic patients is one of the most controversial issues of vascular surgery throughout the last decades. Two randomized trials Asymptomatic Carotid Atherosclerosis Study (ACAS) and Asymptomatic Carotid Surgery Trial (ACST) are still remain cornerstone of guidelines and both study showed marked reduction in 5-year risk of stroke (50\% relative risk reduction) in patients who had $\mathrm{CEA}^{(9,10)}$. Ten years result of ACST-1 trial reported that in comparison to conservative treatment CEA has retained a positive long-term effect on the reduction of all form of stroke. The absolute risk reduction $6.1 \%$ between surgical and conservative arm, carotid endarterectomy (CEA) showed a $46 \%$ reduction in the incidence of all strokes ${ }^{(11)}$.

Because of the general lack of certainty about whether carotid revascularization is needed in individuals with asymptomatic disease, it's important to search answers of following questions before attempting to any intervention.

\section{What is the Incidence of Significant Carotid Stenosis in Patients Undergoing CABG?}

Current guidelines do not support routine screening for carotid artery stenosis before $\mathrm{CABG}$ because of given the low prevalence of stroke after $\mathrm{CABG}^{(4,6,12)}$. Most of the available evidence did not suggest casual relationship between a significant asymptomatic unilateral stenosis and post-CABG stroke ${ }^{(12)}$. Schoof et al. ${ }^{(5)}$ reported that $94 \%$ of patients who suffered a stroke following cardiac surgery did not have a significant carotid stenosis.

One of the largest analysis of the prevalence of concomitant coronary and carotid atherosclerotic disease reported that the presence of internal carotid artery 
stenosis is directly related to the extent of CAD, though the prevalence of moderate and severe carotid stenosis in patients with CAD is lower than previously reported ${ }^{(13,14)}$. They had found severe carotid stenosis $(>70 \%)$ in $7 \%$ among patients with three vessel CAD whereas this ratio decreases to $2 \%$ in patients with nonobstructive CAD. In patients below 70 years of age, prevalence of severe carotid disease decreases to $0.8 \%$ in male, $0.2 \%$ in women. Several studies have shown that the existence of bilateral moderate to severe carotid artery stenosis in ultrasound screened patients prior to cardiac surgery were found between 2.2 to $2.6 \%$ in patients undergoing $\mathrm{CABG}^{(15-17)}$.

\section{Does Untreated Asymptomatic Carotid Stenosis was Associated with an Increased Risk of Stroke After Cardiac Surgery?}

The main question we faced is, what is the prevalence of perioperative stroke in neurologically asymptomatic patients with unilateral or bilateral carotid stenosis who undergoing to cardiac surgery without prophylactic CEA? Several studies included patients with both unilateral and bilateral $50-99 \%$ stenosis reported that 30-day risk of stroke was between $2 \%$ and $4.8 \%$ and perioperative death was between $2 \%$ and $6.5 \%{ }^{(6,18-21)}$. Cardiac surgery patients with untreated asymptomatic $70-99 \%$ carotid stenosis incurred a 30 -day stroke risk of only $2 \%$ and death/stroke rate of $4.8 \%$ was found in another meta-analysis ${ }^{(6,20)}$. However, due to relatively small numbers of these studies, it was not easy to reach statistically meaningful conclusion. The 30-day risk of death/stroke was 9.1\% in asymptomatic patients with bilateral carotid disease following isolated cardiac surgery which shows higher risk than patients with unilateral disease ${ }^{(6,22)}$. Also, patients who described a history of stroke were significantly more likely $(\mathrm{OR}=3.6)$ to have further stroke than those who were asymptomatic ${ }^{(4)}$. Santarpino et al. ${ }^{(7)}$ reported that among 649 patients with asymptomatic carotid artery stenosis $>50 \%$ undergoing isolated $\mathrm{CABG}$, the incidence of postoperative stroke was $1.5 \%$ and the risk of stroke were significant only in patients with a stenosis ${ }^{3} 90 \%$ $(\mathrm{OR}=12, \mathrm{CI}=1.4-33.3)$. They concluded as asymptomatic, severe carotid artery stenosis has a low prevalence and when left untreated is associated with a relatively low risk of postoperative stroke.

\section{Does Concomitant CEA Procedure in Patients with Asymptomatic Carotid Disease Who Undergoing CABG Reduce Post-operative Incidence of Stroke?}

Since the first report by Bernhard et al. ${ }^{(23)}$ in 1972, in many centers, synchronous CEA and cardiac procedure has become routine practice. Because almost $80 \%$ of strokes are not preceded by TIA or minor strokes, preventing the risk of post-cardiopulmonary bypass strokes in asymptomatic patients by concomitant CEA is a sensible justification. But we need to clarify the procedural risk of the patients with bilateral carotid disease who have unilateral CEA then undergo cardiac surgery in the presence of an unoperated (contralateral) stenosis or occlusion.

Antoniou et al. ${ }^{(24)}$ in their systematic review reported that patients undergoing CEA in the presence of an occluded contralateral carotid artery had increased incidence of stroke $(\mathrm{OR}=1,65, \mathrm{CI}=1.3-2.1)$ and death $(\mathrm{OR}=1.76, \mathrm{CI}=1.2-2.5)$ in 30-day of treatment compared with those with a patent contralateral carotid artery.

Studies reporting outcomes following staged/ synchronous carotid revascularization prior to cardiac surgery have concluded that risk of procedural strokes are reduced ${ }^{(25,26)}$. Nwakanma et al. ${ }^{(27)}$ reported that there was no significant difference in MI, stroke and death at 30-day follow-up between patients undergoing simultaneous CEA-CABG and isolated CABG. Baiou et al. ${ }^{(19)}$ challenged the opinion that prophylactic CEA can be expected to significant reduce the risk of stroke in patients with asymptomatic carotid artery disease needs to cardiac surgery. However, they found that no strokes occurred in 61 consecutive open cardiac procedures in patients with asymptomatic severe unilateral carotid stenosis who did not undergo prophylactic CEA.

In the CABACS trial ${ }^{(28)}$, patients with asymptomatic carotid stenosis, and with an indication for coronary 
surgical revascularization, were randomized to receive combined CEA with CABG versus CABG alone. Rates of stroke and death were in general higher than reported in some other studies, this could be possible due to relatively high risk and older population. Although not statistically different, the isolated CABG group tended to do better than did the combined procedure group (the 30-day and 1-year combined stroke/death rates were $18.5 \%$ and $23.4 \%$, in the combined CEA/CABG group, and were $9.7 \%$ and $13.1 \%$ in the isolated CABG group).

\section{What are the Surgical Options for CEA; Synchronous or Staged Approach? On-pump vs Off-pump?}

Optimal surgical intervention and timing for patients having concomitant severe carotid and coronary artery stenosis remains uncertain. A hypothesis for the higher death and stroke rates is that combined procedures reveal higher operative stress, prolonged operative time and instability in hemodynamics on cardiac and cerebrovascular system ${ }^{(29)}$. There are different surgical techniques which can be chosen depending on patient status and characteristics of carotid disease. There seems to be no considerable difference in total vascular mortality and morbidity between two approaches. Synchronous CEA and CABG approach comparing with staged (prior) CEA requires only one anesthesia and has less risk of myocardial infarction while waiting for $\mathrm{CABG}$. On the contrary, overall stroke risk seems to be lower with staged CEA than with synchronous CEA. In their meta-analysis of observational studies, Sharma et al. ${ }^{(30)}$ reported that outcomes in combined and staged approach for synchronous CEA and CABG were similar therefore they suggest that the two strategies can be used interchangeable in the clinical practice depending on specific clinical conditions.

Feldman et al. ${ }^{(31)}$ reported comparison of trends and in hospital outcomes of concurrent carotid artery revascularization and $\mathrm{CABG}$ in USA from the Nationwide Inpatient Sample (NIS) database between 2004 and 2012. During the 9-year period, they found
22,501 concurrent carotid revascularization and CABG during the same hospitalization, $68 \%$ of these patients underwent combined CEA plus CABG, 28\% underwent staged CEA plus $\mathrm{CABG}$ and $3.6 \%$ underwent staged carotid stent (CAS) plus CABG. The adjusted risk of death was greater, whereas risk of stroke was lower with both combined CEA-CABG (stroke $\mathrm{OR}=0,65$ ) and staged CEA-CABG (stroke $\mathrm{OR}=0.50$ ) approaches compared with $\mathrm{CAS}-\mathrm{CABG} \mathrm{G}^{(31)}$

Illuminati et al. $^{(32)}$ reported that in 185 patients with unilateral asymptomatic carotid stenosis $>70 \%$, randomized two groups, one group of patients received a CABG with previous or simultaneous CEA and another group of patients underwent $\mathrm{CABG}$, followed by CEA. The 90-day stroke and death rate was $1.0 \%$ in synchronous group, $8.8 \%$ in delayed group (Odds ratio $=0.11$ ). They conclude that $\mathrm{CEA}$ before $\mathrm{CABG}$ or combined with $\mathrm{CABG}$ can prevent stroke better in patients with an asymptomatic severe carotid stenosis than delayed $\mathrm{CEA}^{(32)}$.

Gopaldas et al. ${ }^{(33)}$ identified from NIS database 1998 to 2007,6153 patients who underwent CEA before or after CABG during the same hospital admission (staged) and 16639 patients who underwent both procedures on the same day (synchronous). They found that mortality $(4.2 \%$ vs $4.5 \%)$ and neurologic complications $(3.5 \%$ vs $3.9 \%$ ) were similar between the staged and synchronous groups. Their subgroup analysis comparing on-pump and off-pump CABG which was performed within the staged and synchronous groups showed that performing offpump CABG did not affect combined death-stroke rates in both groups. However, they reported that on-pump CABG was associated with an elevated risk of stroke in synchronous group $(\mathrm{OR}=1.55, \mathrm{CI}=1.27-1.91)$ but not in staged patients ${ }^{(33)}$.

In the literature, reported rate of mortality is between $0-4.5 \%$ and rate of stroke is between $0-3.1 \%$ for combined CEA and off-pump $\mathrm{CABG}^{(34-39)}$. Eren et al. ${ }^{(35)}$ reported no stroke and $3.7 \%$ mortality for patients who had CEA and simultaneous off-pump CABG. Nabagiez et al. ${ }^{(36)}$ suggested that twenty-four hour staged CEA followed 
by off-pump CABG minimizes post-CEA myocardial infarction while minimizing cerebrovascular accident post-CABG in patients with concomitant severe coronary and carotid artery disease. In order to comparison of early outcomes with three different approaches for combined CEA-CABG, Dönmez et al. ${ }^{(37)}$ reported that no any further benefit with off-pump technique compared to onpump technique, except for shorter intensive care unit and hospitalization times.

Shishehbor et al. ${ }^{(38)}$ evaluated three approaches to carotid revascularization in $\mathrm{CABG}$ patients with asymptomatic carotid stenosis, staged CEA-CABG, combined CEA-CABG and staged carotid artery stenting (CAS)-CABG. They reported that combined CEA-CABG and staged $\mathrm{CAS}-\mathrm{CABG}$ were associated with similar rates of stroke, death and MI in both groups but higher MI rates in the staged CEA-CABG group.

Khaitan et al. ${ }^{(39)}$ reported simultaneous CEA and CABG during single cross-clamp, under $25^{\circ} \mathrm{C}$ of hypothermia for further cerebral protection, as a safe technique with a mortality rate of $5.8 \%$ and stroke incidence of $5.8 \%$. Their assert was that systemic hypothermia reduces the metabolic tissue rate and is employed for neuroprotection during cardiac and aortic surgeries ${ }^{(39)}$. Guibaud et al. ${ }^{(40)}$ also stated hypothermia below $28^{\circ} \mathrm{C}$ provides better cerebral protection especially for patients with bilateral carotid lesions. In contrast to this benefit, hypothermia during CEA had found to increase risk of $\mathrm{MI}(\mathrm{OR}=3.5, \mathrm{CI}=0.8$ 15.5) due to increased cross clamp and cardiopulmonary bypass times ${ }^{(37)}$.

\section{What are the Predictors Associated with Stroke After CABG?}

Advanced age, prior cerebrovascular disease/stroke, severity of carotid artery stenosis and peripheral vascular disease, presence of contralateral carotid occlusion and porcelain ascending aorta, postoperative IABP or ECMO supporting, unstable angina, urgency of the procedure, prolonged cardiopulmonary bypass time and postoperative atrial fibrillations were reported as the most consistent independent predictors of perioperative stroke after $\mathrm{CABG}^{(7,41,42)}$. Gender, diabetes mellitus, hypertension, prior myocardial infarction, chronic renal failure and congestive heart failure showed contradictive results ${ }^{(7)}$.

Post hoc analysis results of the NASCET and ACAS trials suggested that CEA may not be efficacious in women as it is in men ${ }^{(9,43)}$. Sarac et al. ${ }^{(44)}$ reported that univariate results of 3077 consecutive patients who the ratio of men to women 2:1, results of gender differences revealed that women were higher risk for a postoperative stroke or mortality (3.1\% for women, $2.1 \%$ for men; OR=1.6 $\mathrm{CI}=1.04-2.5)$ and also they found that female gender was an independent predictor $(\mathrm{OR}=1.7 ; \mathrm{CI}=1.1-2.6)$ for a postoperative TIA or stroke.

\section{How Can We Identify Vulnerable Carotid Plaque?}

Risk stratification for carotid stenosis generally has been based on angiographic or Doppler ultrasonographic examination of luminal stenosis but we need to identify vulnerable carotid plaque by using more sophisticated methods such as positron emission tomography with computed tomography, magnetic resonance imaging (MRI), contrast enhanced ultrasound techniques and detection of micro-embolism using transcranial Doppler (TCD) ultrasound ${ }^{(45-50)}$. The pattern of progression of carotid stenosis is unpredictable and it may progress rapidly or slowly or remain stable in long term period ${ }^{(46)}$. Intimal wall thickening, increased echolucency, a low gray-scale median, lipid rich necrotic plaque core and plaque ulceration are the features of plaque itself which have been carried burden of risk of future stroke ${ }^{(47)}$.

Detection of subclinical embolization or silent cerebral ischemic events may prove useful in identifying asymptomatic patients at high risk of stroke. The Asymptomatic Carotid Emboli Study was a multicenter prospective observational study aiming to investigate whether detection of asymptomatic embolic signals by use of TCD could predict stroke risk in patients with asymptomatic carotid stenosis ${ }^{(48)}$. The hazard ratio for the 
risk of ipsilateral stroke and TIA for those with embolic signals compared with those without was $7.57(\mathrm{CI}=2.32$ 24.6). They concluded that TCD can identify groups of patients with asymptomatic carotid stenosis who are at low or high risk of future stroke ${ }^{(48)}$.

Kakkos et al. ${ }^{(49)}$ tested the hypothesis that the size of a juxtaluminal black (hypoechoic) area (JBA) in ultrasound images of asymptomatic carotid artery plaques predicts future ipsilateral ischemic stroke. They conclude that the concept of plaque heterogeneity and plaque with a large JBA can be used for stroke risk stratification.

Measuring carotid plaque volume (CPV) by minimally invasive tomographic ultrasound imaging and MRI suggested that CPV was associated with cardiovascular risk factors and symptoms of cerebral ischemia ${ }^{(50,51)}$. Ball et al. ${ }^{(50)}$ reported that CPV correlated with symptoms of cerebral ischemia but not carotid stenosis and it could be a potential indicator for CEA. To investigate the association between MR imaging-depicted intraplaque hemorrhage (IPH) in the carotid artery wall and the risk of future ipsilateral cerebrovascular events in men with asymptomatic moderate carotid stenosis, Singh et al. ${ }^{(52)}$ reported that MR-depicted IPH was associated with an increased risk of cerebrovascular events $(\mathrm{HR}=3.59$ $\mathrm{CI}=2.4-4.7$, negative predictive value $=100 \%$ ).

\section{Guidelines Recommendations for the Treatment of Asymptomatic Carotid Stenosis in Coronary Artery Bypass Patients}

Clinical Practice Guidelines of the European Society for Vascular Surgery in $2017^{(12)}$ recommend that a staged or synchronous carotid intervention is not recommended in coronary artery bypass patients with an asymptomatic unilateral $70-99 \%$ carotid stenosis for the prevention of stroke after coronary bypass (Class III, level C). A staged or synchronous carotid intervention may be considered in coronary artery bypass patients with bilateral asymptomatic $70-99 \%$ carotid stenosis or a 70 99\% stenosis with contralateral occlusion (Class IIB, level C). The choice between carotid endarterectomy and carotid stenting in whom a carotid intervention is deemed necessary prior to CABG should be based on the urgency of performing surgery, choice of antiplatelet strategy during $\mathrm{CABG}$, individual patient characteristics, symptoms and local expertise (Class IIa, level C).

\section{Conclusion}

The decision about how to manage asymptomatic carotid disease in the setting of planned CABG becomes more complex due to surgical treatment of either pathology may be complicated by multiple factors. In routine clinical practice, the indication to CEA is usually based on symptoms and severity of stenosis. Meticulous screening for carotid disease to identifying high risk patients who have vulnerable plaque is one of the most crucial part of this conundrum. Synchronous or staged CEA still remain valuable options in order to diminish postoperative risk of stroke for neurologically asymptomatic patients who have bilateral significant carotid artery stenosis or contralateral occlusion undergoing to CABG. But these group of patients are relatively small proportion of asymptomatic patients who needs to $\mathrm{CABG}$. Because of the low rate of stroke in uncomplicated patients who have combined CEA and $\mathrm{CABG}$, synchronous $\mathrm{CEA}-\mathrm{CABG}$ procedure can be recommended in asymptomatic men below 75 years old with a critical unilateral suspected carotid plaque $>80 \%$ stenosis if the expected perioperative stroke/death rate is $<3 \%$. The majority of patients undergoing CABG have asymptomatic unilateral carotid stenosis and it seems rationale to leaving the low risk patients to be treated medically when considering insignificant stroke rate of these untreated carotid disease.

\section{Ethics}

Peer-review: Internally peer-reviewed.

Financial Disclosure: The author declared that this study received no financial support.

\section{References}

1. Nichols M, Townsend N, Luengo-Fernandez R, et al. European cardiovascular disease statistics 2012. European Heart Network, Brussels, European Society of Cardiology, Sophia Antipolis. 
2. Eascott HH, Pickering GW, Rob CG. Reconstruction of internal carotid artery in a patient with intermittent attacks of hemiplegia. Lancet 1954;267:994-6.

3. Kapetanakis EI, Stamou SC, Dullum MK, et al. The impact of aortic manipulation on neurologic outcomes after coronary artery bypass surgery: a risk adjusted study. Ann Thorac Surg 2004;78:1564-71.

4. Naylor AR, Mehta Z, Rothwell PM, Bell PRF. Carotid artery disease and stroke during coronary artery bypass: a critical review of the literature. Eur J Vasc Endovasc Surg 2002;23:283-94.

5. Schoof J, Lubahn W, Baerner M, et al. Impaired cerebral autoregulation distal to carotid stenosis/occlusion is associated with an increased risk of stroke with cardiopulmonary bypass. J Thorac Cardiovasc Surg 2007;134:690-6.

6. Naylor AR, Bown MJ. Stroke after cardiac surgery and its association with asymptomatic carotid disease: an updated systematic review and metaanalysis. Eur J Vasc Endovasc Surg 2011;41:607-24.

7. Santarpino G, Nicolini F, De Feo M, et al. Prognostic impact of asymptomatic carotid artery stenosis in patients undergoing coronary artery bypass grafting. Eur J Vasc Endovasc Surg 2018;56:741-8.

8. Nedeltchev K, Pattynama PM, Biaminoo G et al. Standardized definitions and clinical endpoints in carotid artery and supra-aortic trunk revascularization trials. Catheter Cardiovasc Interv 2010;76:333-44.

9. Endarterectomy for asymptomatic carotid artery stenosis. Executive Committee for Asymptomatic Carotid Atherosclerosis Study. JAMA $1995 ; 273: 1421-8$

10. Halliday A, Mansfield A, Marro J. The MRC Asymptomatic Carotid Surgery Trial (ACST): carotid endarterectomy prevents disabling and fatal carotid territory strokes. Lancet 2004;363:1491-502.

11. Halliday AH, Harrison M, Hayter E, et al. 10-year stroke prevention after successful carotid endarterectomy for asymptomatic stenosis (ACST-1): a multicenter randomized trial. Lancet 2010;376:1074-84.

12. Naylor AR, Ricco JB, de Borst GJ, et al. Management of Atherosclerotic Carotid and Vertebral Artery Disease: 2017 Clinical Practice Guidelines of the European Society for Vascular Surgery (ESVS). Eur J Vasc Endovasc Surg 2018;55:3-81.

13. Steinvil A, Sadeh B, Arbel Y, et al. Prevalence and predictors of concomitant carotid and coronary artery atherosclerotic disease. J Am Coll Cardiol 2011;57:779-83.

14. Kallikazaros I, Tsioufis C, Sideris S, et al. Carotid artery disease as a marker for presence of severe coronary artery disease in patients evaluated for chest pain. Stroke 1999;30:1002-7.

15. Wanamaker KM, Moraca RJ, Nitzberg D, et al. Contemporary incidence and risk factors for carotid artery disease in patients referred for coronary artery bypass surgery. J Cardiothorac Surg 2012;7:78.

16. Stamou SC, Hill PC, Dangas G, et al. Stroke after coronary artery bypass: incidence, predictors and clinical outcome. Stroke 2001;32:1508-13.

17. Naylor AR. Why is the management of asymptomatic carotid disease so controversial? The Surgeon 2015;13:34-43.

18. Li Y, Walicki D, Mathiesen C, et al. Strokes after cardiac surgery and relationship to carotid stenosis. Arch Neurol 2009;66:1091-6.
19. Baiou D, Karageorge A, Spyt T, et al. Patients undergoing cardiac surgery with asymptomatic unilateral carotid stenoses have a low risk of perioperative stroke. Eur J Vasc Endovasc Surg 2009;38:556-9.

20. Ghosh J, Murray D, Khwaja N, et al. The influence of asymptomatic significant carotid disease on mortality and morbidity in patients undergoing coronary artery bypass surgery. Eur J Vasc Endovasc Surg 2005;29:88-90.

21. Safa TK, Friedman S, Mehta M, et al. Management of coexisting coronary artery and asymptomatic carotid artery disease: report of a series of patients treated with coronary bypass alone. Eur J Vasc Endovasc Surg 1999:17:249-52.

22. Manabe S, Shimokawa T, Fukui T, et al. Influence of carotid artery stenosis on stroke in patients undergoing off-pump coronary artery bypass grafting. Eur J Cardiothorac Surg 2008;34:1005-8.

23. Bernhard VM, Johnson WD, Peterson JJ. Carotid artery stenosis. Association with surgery for coronary artery disease. Arch Surg 1972;105:837-40.

24. Antoniou GA, Kuhan G, Sfyroeras GS, et al. Contralateral occlusion of the internal carotid artery increases the risk of patients undergoing carotid endarterectomy. J Vasc Surg 2013;57:1134-45.

25. Timaran CH, Rosero EB, Smith ST, et al. Trends and outcomes of concurrent carotid revascularization and coronary bypass. J Vasc Surg 2008;48:355-60.

26. Naylor AR. Synchronous cardiac and carotid revascularization: the devil is in the detail. Eur J Vasc Endovasc Surg 2010;40:303-8.

27. Nwakanma L, Poonyagariyagom HK, Bello R, et al. Early and late results of combined carotid endarterectomy and coronary artery bypass versus isolated coronary artery bypass. Interact Cardiovasc Thorac Surg 2006;5:159-65.

28. Weimar C, Bilbilis K, Rekowski J, et al. Safety of simultaneous coronary artery bypass grafting and carotid endarterectomy versus isolated coronary artery bypass grafting (CABACS). A randomized clinical trial. Stroke 2017;48:2769-75

29. Ogutu P, Werner R, Oertel F, et al. Should patients with asymptomatic significant carotid stenosis undergo simultaneous carotid and cardiac surgery? Interact Cardiovasc Thorac Surg 2014;18:511-8.

30. Sharma V, Deo SV, Park SJ, et al. Meta-analysis of staged versus combined carotid endarterectomy and coronary artery bypass grafting. Ann Thorac Surg 2014;97:102-9.

31. Feldman DN, Swaminathan RV, Geleris JD, et al. Comparison of trends and in-hospital outcomes of concurrent carotid artery revascularization and coronary artery bypass graft surgery. J Am Coll Cardiol 2017;10:286-98.

32. Illuminati G, Ricco JB, Caliò F, et al. Short-term results of a randomized trial examining timing of carotid endarterectomy in patients with severe asymptomatic unilateral carotid stenosis undergoing coronary artery bypass grafting. J Vasc Surg 2011;54:998-9.

33. Gopaldas RR, Chu D, Dao TK, et al. Staged versus synchronous carotid endarterectomy and coronary artery bypass grafting: Analysis of 10-year nationwide outcomes. Ann Thorac Surg 2011;91:1323-9.

34. Fareed KR, Rothwell PM, Mehta Z, et al. Synchronous carotid endarterectomy and off-pump coronary bypass: an updated, systematic review of early outcomes. Eur J Vasc Endovasc Surg 2009;37;375-8.

35. Eren E, Balkanay M, Toker ME, et al. Simultaneous carotid endarterectomy and coronary revascularization is safe using either on-pump or off-pump technique. Int Heart J 2005;46:783-93. 
36. Nabagiez JP, Bowman KC, Shariff MA, et al. Twenty-four hour staged carotid endarterectomy followed by off-pump coronary bypass grafting for patients with concomitant carotid and coronary disease. Ann Thorac Surg 2014;98:1613-8.

37. Dönmez A, Adademir T, Sacli H, et al. Comparison of early outcomes with three approaches for combined coronary revascularization and carotid endarterectomy. Braz J Cardiovasc Surg 2016;31:365-70.

38. Shishehbor MH, Venkatachalam S, Sun Z, et al. A direct comparison of early and late outcomes with three approaches to carotid revascularization and open heart surgery. J Am Coll Cardiol 2013;62:948-56.

39. Khaitan L, Sutter FP, Goldman SM, et al. Simultaneous carotid endarterectomy and coronary revascularization. Ann Thorac Surg 2000;69:421-4

40. Guibaud JP, Roques X, Laborde N, et al. Extracorporeal circulation as an additional method for cerebral protection in simultaneous carotid endarterectomy and coronary artery surgical revascularization. J Card Surg 2004;19:415-9.

41. Mao Z, Zhong X, Yin J, et al. Predictors associated with stroke after coronary artery bypass grafting: a systematic review. J Neurol Sci 2015;357:1-7.

42. Faggioli G, Pini R, Mauro R, et al. Contralateral carotid occlusion in endovascular and surgical carotid revascularization: a single center experience with literature review and meta-analysis. Eur J Vasc Endovasc Surg 2013; 46:10-20.

43. Inzitari D, Eliasziw M, Gates P, et al. The North American Symptomatic Carotid Endarterectomy Trial Collaborators. The causes and risk of stroke in patients with asymptomatic internal carotid artery stenosis. N Engl J Med 2000;342:1693-700.
44. Sarac TP, Hertzer NR, Mascha EJ, et al. Gender as a primary predictor of outcome after carotid endarterectomy. J Vasc Surg 2002;35:748-53.

45. Jayasooriya G, Thapar A, Shalhoub J, et al. Silent cerebral events in asymptomatic carotid stenosis. J Vasc Surg 2011;54:227-36.

46. Conrad MF, Baloum V, Mukhopadhyay S, et al. Progression of asymptomatic carotid stenosis despite optimal medical therapy. J Vasc Surg 2013;58:12835 .

47. Kakkos SK, Nicolaides AN, Charalambous I, et al. Predictors and clinical significance of progression or regression of asymptomatic carotid stenosis. J Vasc Surg 2014;59:956-67.

48. Markus H, King A, Shipley M, et al. Asymptomatic embolization for prediction of stroke in the Asymptomatic Carotid Emboli Study (ACES): a prospective observational study. Lancet Neurol 2010;9:663-71.

49. Kakkos SK, Griffin MB, Nicolaides AN, et al. The size of juxtaluminal hypoechoic area in ultrasound images of asymptomatic carotid plaques predicts the occurence of stroke. J Vasc Surg 2013;57:609-18.

50. Ball S, Rogers S, Kanesalingam K, et al. Carotid plaque volüme in patients undergoing carotid endarterectomy. Br J Surg 2018;105:262-9.

51. Zhao H, Zhao X, Liu X, et al. Association of carotid atherosclerotic plaque features with acute ischemic stroke: a magnetic resonance imaging study. Eur J Radiol 2013;82:e465-70.

52. Singh N, Moody AR, Gladstone DJ, et al. Moderate carotid artery stenosis: MR imaging-depicted intraplaque hemorrhage predicts risk of cerebrovascular ischemic events in asymptomatic men. Radiology $2009 ; 252: 502-8$ 